\title{
A sector-based nonparametric decomposition of economic growth
}

\author{
Barnabé Walheer* \\ HEC Liége, Université de Liége, Belgium
}

Received: 3 July 2019

Revised: 6 November 2019

Accepted: 15 November 2019

\begin{abstract}
Sectors have gained in importance when studying economic growth and convergence of countries. In this letter, we suggest a simple and intuitive nonparametric procedure to obtain the decomposition of economic growth of countries in terms of sector-level indicators. It turns out that the new decomposition can be used to investigate the role of the sectors in the economic growth and convergence of countries. We propose an application to the case of 19 countries and nine sectors in Europe.
\end{abstract}

Keywords: growth; convergence; sector; Data Envelopment Analysis; Europe JEL Classification Codes: O4

\section{Introduction}

Decomposing economic growth into different components dates back to the seminal work of Solow (1956). This operation is attractive for providing better understanding of the sources and causes of countries' economic growth and convergence. A less desirable feature of the decomposition is its dependency on a functional form for the technology, captured, in practice, by a production function. Solow's decomposition was based on a Cobb-Douglas production function, but others, such as a trans-log or a CES production function, can be used as an alternative. In many cases, choosing a specific production function appears to be complex, but also and more essentially can have a significant impact on the relative importance of the decomposition components.

Building on this drawback for the economic growth decomposition, Kumar and Russell (2002) suggested a Data Envelopment Analysis (DEA)-based economic growth decomposition. DEA, introduced by Charnes, Cooper, and Rhodes (1978), did not assume any functional form for the technology, but instead reconstructed the technology using data. As such, contrary to Solow's decomposition, the DEA-based decomposition did not depend on a functional form for the production function. It has since been extended by Henderson and Russell (2005) for human capital, Badunenko and Romero-Avila (2013) for financial institutions, Walheer (2016a, b) for

\footnotetext{
*E-mail: barnabe.walheer@uliege.be.

Citation: Walheer, B. (2020) A sector-based nonparametric decomposition of economic growth, Economics and Business Letters, 9(2), 48-55.
}

DOI: 10.17811/ebl.9.2.2020.48-55 
sector heterogeneity and interdependence, Walheer (2018b) for foreign capital, and Walheer (2018c) for energy.

Recently, there has been increasing attention to studying economic growth at the sector level: Iscan (2015), Zeira and Zoabi (2015), Walheer (2016a, b, 2018a, 2019), Magalhaes and AfIonso (2017), and Battisti, Del Gatto and Parmeter (2018) to cite but a few. These authors' work commonly acknowledges that sectors are heterogeneous with respect to their production process. Nevertheless, no systematic method has been introduced to investigate the sectors' contribution for the countries' economic growth and convergence. In this letter, we propose a simple procedure to obtain the decomposition of economic growth in terms of sector-level concepts exclusively, while keeping the sectors' heterogeneity. In fact, our procedure relies on an aggregation scheme that combines some desirable properties (e.g. endogenous, simple to interpret, and easy to compute weights) and is coherent with economic intuition. As such, it naturally enables us to study the role of the sectors in the economic growth and convergence of countries.

The rest of the letter unfolds as follows: we explain our technique in Section 2; and present an empirical application to 19 countries and nine sectors in Europe in Section 3.

\section{Methodology}

Assume we observe a sample of $J$ countries partitioned into $S$ sectors. Kumar and Russell (2002) showed that economic growth for every country $j=1, \ldots, J$ between a base and a current period, denoted $b$ and $c$, can be decomposed into three sources: change in efficiency $(E F F)$, technological change (TECH), and capital accumulation (KACC). Formally, by denoting $y^{b}$ and $y^{c}$ as the outputs per worker and $g^{b c}$ as the economic growth of country $j$, we have:

$$
\begin{gathered}
g_{j}^{b c}=\frac{y_{j}^{c}}{y_{j}^{b}}=\frac{E F F_{j}^{c}}{E F F_{j}^{b}} x\left(\operatorname{TECH}_{j}^{b} \times \mathrm{TECH}_{j}^{c}\right)^{1 / 2} x\left(\operatorname{KACC}_{j}^{b} \times K A C C_{j}^{c}\right)^{1 / 2}, \\
=E F F_{j} \times \mathrm{TECH}_{j} \times \mathrm{KACC}_{j} .
\end{gathered}
$$

Additionally, let $y_{j}^{b}\left(k_{j}^{b}\right)$ and $y_{j}^{c}\left(k_{j}^{c}\right)$ be the countries' production functions at time $\mathrm{b}$ and $\mathrm{c}$, respectively; where $k_{j}^{b}$ and $k_{j}^{c}$ are the stock of physical capital per worker for the countries. Attractively, the decomposition only depends on the production functions in the following fashion:

$$
\begin{gathered}
E F F_{j}^{b}=\frac{y_{j}^{b}}{y_{j}^{b}\left(k_{j}^{b}\right)}, E F F_{j}^{c}=\frac{y_{j}^{c}}{y_{j}^{c}\left(k_{j}^{c}\right)}, T E C H_{j}^{b}=\frac{y_{j}^{c}\left(k_{j}^{b}\right)}{y_{j}^{b}\left(k_{j}^{b}\right)}, T E C H_{j}^{c}=\frac{y_{j}^{c}\left(k_{j}^{c}\right)}{y_{j}^{b}\left(k_{j}^{c}\right)}, \\
K A C C_{j}^{b}=\frac{y_{j}^{b}\left(k_{j}^{c}\right)}{y_{j}^{b}\left(k_{j}^{b}\right)} \text { and } K A C C_{j}^{c}=\frac{y_{j}^{c}\left(k_{j}^{c}\right)}{y_{j}^{c}\left(k_{j}^{b}\right)} .
\end{gathered}
$$

A similar decomposition can be applied to every sector $s=1, \ldots, S$ in each country. Let us denote $g_{j s}^{b c}, y_{j s}^{b}, y_{j s}^{c}, k_{j s}^{b}, k_{j s}^{c}, y_{j s}^{b}\left(k_{j s}^{b}\right)$ and $y_{j s}^{c}\left(k_{j s}^{c}\right)$ as the economic growth, the outputs, the capital stocks, and the production functions, for every sector $s=1, \ldots, S$ in each country $j=$ $1, \ldots, J$. We obtain:

$$
\begin{gathered}
g_{j s}^{b c}=\frac{y_{j s}^{c}}{y_{j s}^{b}}=\frac{E F F_{j s}^{c}}{E F F_{j s}^{b}} x\left(T E C H_{j s}^{b} \times T E C H_{j s}^{c}\right)^{1 / 2} x\left(K A C C_{j s}^{b} \times K A C C_{j s}^{c}\right)^{1 / 2}, \\
=E F F_{j s} \times \operatorname{TECH}_{j s} \times K A C C_{j s}
\end{gathered}
$$


where $E F F_{j s}^{b}=\frac{y_{j s}^{b}}{y_{j s}^{b}\left(k_{j s}^{b}\right)}, E F F_{j s}^{c}=\frac{y_{j s}^{c}}{y_{j s}^{c}\left(k_{j s}^{c}\right)}, T E C H_{j s}^{b}=\frac{y_{j s}^{c}\left(k_{j s}^{b}\right)}{y_{j s}^{b}\left(k_{j s}^{b}\right)}, T E C H_{j s}^{c}=\frac{y_{j s}^{c}\left(k_{j s}^{c}\right)}{y_{j s}^{b}\left(k_{j s}^{c}\right)}, K A C C_{j s}^{b}=$ $\frac{y_{j s}^{b}\left(k_{j s}^{c}\right)}{y_{j s}^{b}\left(k_{j s}^{b}\right)}$ and $K A C C_{j s}^{c}=\frac{y_{j s}^{c}\left(k_{j s}^{c}\right)}{y_{j s}^{c}\left(k_{j s}^{b}\right)}$ are the components of sector $s$ in country $j$.

We now show how the country-level decomposition can be defined in terms of sector-level concepts exclusively. An initial observation is that the economic growths at both levels can be related as follows

$$
g_{j}^{b c}=\frac{y_{j}^{c}}{y_{j}^{b}}=\frac{\sum_{s=1}^{S} y_{j s}^{c}}{\sum_{s=1}^{S} y_{j s}^{b}}=\sum_{s=1}^{S} \frac{y_{j s}^{c}}{\sum_{S=1}^{S} y_{j s}^{b}} \frac{y_{j s}^{b}}{y_{j s}^{b}}=\sum_{s=1}^{S} \frac{y_{j s}^{b}}{\sum_{s=1}^{S} y_{j s}^{b}} \frac{y_{j s}^{c}}{y_{j s}^{b}}=\sum_{s=1}^{S} \frac{y_{j s}^{b}}{y_{j}^{b}} g_{j s}^{b c} .
$$

In words, economic growth at the country level is a weighted sum of the sector-level economic growths, where the weights are the relative output shares of the sectors at the base year. These weights are exogenous as given by the data, and match with economic intuition. $j$ :

We can apply this principle to the components of the economic growth decomposition of country

$$
\begin{aligned}
& E F F_{j}^{b}=\frac{y_{j}^{b}}{y_{j}^{b}\left(k_{j}^{b}\right)}=\frac{\sum_{s=1}^{S} y_{j s}^{b}}{\sum_{s=1}^{S} y_{j s}^{b}\left(k_{j s}^{b}\right)}=\sum_{s=1}^{S} \frac{y_{j s}^{b}\left(k_{j s}^{b}\right)}{\sum_{s=1}^{S} y_{j s}^{b}\left(k_{j s}^{b}\right)} \frac{y_{j s}^{b}}{y_{j s}^{b}\left(k_{j s}^{b}\right)}=\sum_{s=1}^{S} \frac{y_{j s}^{b}\left(k_{j s}^{b}\right)}{y_{j}^{b}\left(k_{j}^{b}\right)} E F F_{j s}^{b} . \\
& E F F_{j}^{c}=\frac{y_{j}^{c}}{y_{j}^{c}\left(k_{j}^{c}\right)}=\frac{\sum_{s=1}^{S} y_{j s}^{c}}{\sum_{s=1}^{S} y_{j s}^{c}\left(k_{j s}^{c}\right)}=\sum_{S=1}^{S} \frac{y_{j s}^{c}\left(k_{j s}^{c}\right)}{\sum_{S=1}^{S} y_{j s}^{c}\left(k_{j s}^{c}\right)} \frac{y_{j s}^{c}}{y_{j s}^{c}\left(k_{j S}^{c}\right)}=\sum_{S=1}^{S} \frac{y_{j s}^{c}\left(k_{j s}^{c}\right)}{y_{j}^{c}\left(k_{j}^{c}\right)} E F F_{j s}^{c} . \\
& T E C H_{j}^{b}=\frac{y_{j}^{c}\left(k_{j}^{b}\right)}{y_{j}^{b}\left(k_{j}^{b}\right)}=\frac{\sum_{s=1}^{S} y_{j s}^{c}\left(k_{j s}^{b}\right)}{\sum_{S=1}^{S} y_{j s}^{b}\left(k_{j s}^{b}\right)}=\sum_{s=1}^{S} \frac{y_{j s}^{b}\left(k_{j s}^{b}\right)}{\sum_{s=1}^{S} y_{j s}^{b}\left(k_{j s}^{b}\right)} \frac{y_{j s}^{c}\left(k_{j s}^{b}\right)}{y_{j s}^{b}\left(k_{j s}^{b}\right)}=\sum_{s=1}^{S} \frac{y_{j s}^{b}\left(k_{j s}^{b}\right)}{y_{j}^{b}\left(k_{j}^{b}\right)} T E C H_{j s}^{b} . \\
& T E C H_{j}^{c}=\frac{y_{j}^{c}\left(k_{j}^{c}\right)}{y_{j}^{b}\left(k_{j}^{c}\right)}=\frac{\sum_{s=1}^{S} y_{j s}^{c}\left(k_{j s}^{c}\right)}{\sum_{S=1}^{S} y_{j s}^{b}\left(k_{j s}^{c}\right)}=\sum_{s=1}^{S} \frac{y_{j s}^{b}\left(k_{j s}^{c}\right)}{\sum_{s=1}^{S} y_{j s}^{b}\left(k_{j s}^{c}\right)} \frac{y_{j s}^{c}\left(k_{j s}^{c}\right)}{y_{j s}^{b}\left(k_{j s}^{c}\right)}=\sum_{s=1}^{S} \frac{y_{j s}^{b}\left(k_{j s}^{c}\right)}{y_{j}^{b}\left(k_{j}^{c}\right)} T E C H_{j s}^{c} . \\
& K A C C_{j}^{b}=\frac{y_{j}^{b}\left(k_{j}^{c}\right)}{y_{j}^{b}\left(k_{j}^{b}\right)}=\frac{\sum_{s=1}^{S} y_{j s}^{b}\left(k_{j s}^{c}\right)}{\sum_{s=1}^{S} y_{j s}^{b}\left(k_{j s}^{b}\right)}=\sum_{s=1}^{S} \frac{y_{j s}^{b}\left(k_{j s}^{b}\right)}{\sum_{s=1}^{S} y_{j s}^{b}\left(k_{j s}^{b}\right)} \frac{y_{j s}^{b}\left(k_{j s}^{c}\right)}{y_{j s}^{b}\left(k_{j s}^{b}\right)}=\sum_{s=1}^{S} \frac{y_{j s}^{b}\left(k_{j s}^{b}\right)}{y_{j}^{b}\left(k_{j}^{b}\right)} K A C C_{j s}^{b} . \\
& K A C C_{j}^{c}=\frac{y_{j}^{c}\left(k_{j}^{c}\right)}{y_{j}^{c}\left(k_{j}^{b}\right)}=\frac{\sum_{S=1}^{S} y_{j s}^{c}\left(k_{j s}^{c}\right)}{\sum_{S=1}^{S} y_{j s}^{c}\left(k_{j s}^{b}\right)}=\sum_{S=1}^{S} \frac{y_{j s}^{c}\left(k_{j s}^{b}\right)}{\sum_{S=1}^{S} y_{j s}^{c}\left(k_{j s}^{b}\right)} \frac{y_{j s}^{c}\left(k_{j s}^{c}\right)}{y_{j s}^{c}\left(k_{j s}^{b}\right)}=\sum_{S=1}^{S} \frac{y_{j s}^{c}\left(k_{j s}^{b}\right)}{y_{j}^{c}\left(k_{j}^{b}\right)} K A C C_{j S}^{c} .
\end{aligned}
$$

Thus, we obtain that the country-level components are weighted sums of the sector-level counterparts. Significantly, the weights are fully endogenous as given by the model (i.e. the production functions), and depend on the reference year ( $b$ or $c)$. It implies that, in general, the weights are different for each component. Note that the suggested weights fulfill the denominator rule for aggregation of Färe and Karagiannis (2017), and are coherent with several recent works about aggregating productivity and efficiency; see, for example, Zelenyuk (2016) and Walheer (2018a). In other words, these weights are not ad-hoc, but rather derive from the model and confirm economic intuition since they are conceptually similar to the weights obtained for economic growth rates (see (5)). From an empirical perspective, they advance our understanding of how each sector contributes to the countries' economic growth sources. 
Finally, as for Kumar and Russell's (2002) decomposition, the new decomposition is fully nonparametric in nature as the production functions are obtained by solving a linear program. For example, $y_{j s}^{c}\left(k_{j s}^{b}\right)$ is computed as follows $\left(\mathbf{L P}_{\mathbf{1}}\right)$ :

$$
y_{j s}^{c}\left(k_{j s}^{b}\right)=\max \left\{y \mid y \leq \sum_{\tau=1}^{c} \sum_{j=1}^{J} \lambda_{j s}^{\tau} \mathrm{y}_{j s}^{\tau} ; k_{j s}^{b} \geq \sum_{\tau=1}^{c} \sum_{j=1}^{J} \lambda_{j s}^{\tau} \mathrm{k}_{j s}^{\tau}, \forall \mathrm{j}, \forall \tau: \lambda_{j s}^{\tau} \geq 0 ; y \geq 0\right\} .
$$

That is, a different production function is computed for each sector in every country and time period capturing the heterogeneity in our modelling. At this point, we notice that, generally, the computed production functions are significantly impacted by the presence of outliers and biased. Using the well-established method described in Daraio and Simar (2007), we compute the robust bias-corrected counterparts. Roughly speaking, sub-samples are used when computing the production functions. As a result, the estimators are less sensitive to potential issues.

\section{Empirical study}

We illustrate the usefulness of the sector-based decomposition by considering the case of 19 European countries: Austria, Belgium, the Czech Republic, Denmark, Estonia, Finland, France, Germany, Hungary, Ireland, Italy, Luxembourg, the Netherlands, Norway, Poland, Slovakia, Slovenia, Spain, and Sweden; and nine sectors: Agriculture $(A)$, Manufacturing $(M)$, Electricity, Gas and Water $(E G W)$, Construction $(C)$, Wholesale $(W)$, Transport $(T)$, Public Administration $(P$ ) , Education $(E)$, and Health $(H)$. Data are taken from the OECD Detailed National Accounts database and the time span is 1995-2015 (period $b$ and $c$, respectively). It covers between $72.21 \%-$ $81.21 \%$ of the country-level values for the variables for the period. We correct data for inflation and purchasing power parity.

We start by presenting the economic growth rates in Table 1 . We see greater economic growth for Scandinavian countries. The Electricity, Gas and Water sector is the most important in terms of economic growth; especially in Belgium, Luxembourg, and Spain. Next, the Manufacturing sector and the public-oriented sectors (i.e. Public Administration, Education, and Health) make importantcontributions to the economic growth of countries.

Table 1. Economic growth.

\begin{tabular}{|c|c|c|c|c|c|c|c|c|c|c|}
\hline Country & & $\mathbf{A}$ & $\bar{M}$ & EGW & $\bar{C}$ & $\overline{\mathbf{W}}$ & $\overline{\mathbf{T}}$ & $\mathbf{P}$ & $\mathbf{E}$ & $\overline{\mathbf{H}}$ \\
\hline Austria & 20.10 & 45.68 & 51.78 & 10.03 & 16.38 & 13.67 & 29.94 & 10.71 & 21.02 & 16.16 \\
\hline Belgium & 11.16 & 9.74 & 31.52 & -22.69 & 42.40 & 46.37 & 8.08 & 41.42 & 29.25 & 6.76 \\
\hline Czech Rep. & 12.29 & 34.22 & 45.97 & 26.10 & 28.88 & 21.89 & -20.28 & 46.14 & 22.75 & 31.29 \\
\hline Denmark & 54.74 & -8.66 & 96.52 & 104.32 & 18.82 & 19.22 & 40.62 & 40.50 & 44.30 & 42.29 \\
\hline Estonia & 15.33 & 146.15 & 52.94 & 187.01 & 0.97 & 41.94 & 50.56 & 44.24 & 7.02 & 37.21 \\
\hline Finland & 46.85 & 50.58 & 30.99 & 101.50 & 34.05 & 36.27 & -3.22 & 80.17 & 49.53 & 40.76 \\
\hline France & 37.87 & 8.76 & 36.04 & 76.69 & 28.81 & 10.58 & 6.83 & 38.80 & 34.37 & 13.95 \\
\hline Germany & 44.78 & 34.88 & 70.81 & 94.68 & 36.80 & 26.36 & 30.92 & 65.30 & 32.15 & 11.97 \\
\hline Hungary & 12.10 & 20.31 & 19.20 & 15.23 & 48.39 & 49.57 & 29.52 & 54.41 & 25.22 & 45.59 \\
\hline Ireland & 58.28 & -32.50 & 80.42 & 183.96 & 10.90 & 44.91 & 25.88 & 13.68 & 47.51 & 16.52 \\
\hline Italy & 28.50 & 14.25 & 5.23 & 71.88 & 3.19 & -13.03 & -9.54 & 56.10 & 7.41 & 8.10 \\
\hline Luxembourg & 1.98 & -34.94 & -15.07 & -20.57 & 23.10 & 74.00 & -34.27 & 25.26 & 32.85 & 15.16 \\
\hline Netherlands & 48.95 & 27.54 & 51.58 & 75.05 & 24.73 & 45.02 & 28.04 & 49.22 & 32.54 & 20.73 \\
\hline Norway & 72.32 & -36.46 & 59.46 & 156.65 & 56.66 & 28.73 & 44.17 & 100.30 & 77.66 & 77.12 \\
\hline Poland & 7.24 & -23.90 & 2.92 & 85.99 & 12.86 & 10.04 & 8.74 & -26.82 & 2.23 & 53.29 \\
\hline Slovakia & 22.73 & 166.76 & 28.62 & 100.37 & 102.64 & -6.93 & 6.02 & 43.10 & 70.29 & 46.72 \\
\hline Slovenia & 2.08 & -14.28 & 38.37 & 57.76 & -10.00 & 0.75 & -0.41 & -19.65 & -23.19 & -22.98 \\
\hline Spain & 6.64 & 24.57 & 32.22 & -17.10 & 34.77 & -0.04 & -14.79 & 92.38 & 6.81 & 14.68 \\
\hline Sweden & 57.30 & 16.09 & 85.05 & 47.64 & 57.20 & 70.42 & 43.36 & 93.25 & 61.60 & 92.39 \\
\hline Mean & 29.54 & 23.62 & 42.35 & 70.24 & 30.08 & 27.36 & 14.22 & 44.66 & 30.60 & 29.88 \\
\hline
\end{tabular}


Table 2. Efficiency change.

\begin{tabular}{|c|c|c|c|c|c|c|c|c|c|c|}
\hline Country & & $\mathbf{A}$ & $\mathbf{M}$ & $\begin{array}{c}\text { EGW } \\
\end{array}$ & $\mathrm{C}$ & $\mathbf{W}$ & $\mathbf{T}$ & $\mathbf{P}$ & $\mathbf{E}$ & $\mathbf{H}$ \\
\hline Austria & -31.06 & 6.84 & -29.57 & -45.14 & -14.27 & -27.09 & -22.37 & 3.39 & -8.19 & -7.75 \\
\hline Belgium & -33.00 & -18.99 & -37.26 & -47.60 & 2.99 & -16.19 & -30.95 & 17.83 & -6.47 & -15.43 \\
\hline Czech Rep. & -6.55 & 18.55 & -13.00 & -11.80 & -0.67 & 1.44 & -60.76 & 16.95 & 1.48 & 36.66 \\
\hline Denmark & -7.10 & -18.65 & -19.69 & 3.35 & -6.28 & -4.41 & -12.45 & -2.60 & -6.47 & -11.21 \\
\hline Estonia & 17.91 & 64.60 & 42.79 & -20.31 & -0.65 & 44.91 & 1.36 & 39.17 & 9.81 & 40.32 \\
\hline Finland & -21.36 & 26.09 & -36.76 & -32.28 & -4.89 & -27.38 & -30.38 & -1.07 & 2.38 & -21.89 \\
\hline France & -24.09 & -15.58 & -34.05 & -36.94 & -11.51 & -23.10 & -41.48 & 1.29 & 23.58 & -6.01 \\
\hline Germany & -4.95 & 2.19 & -25.62 & 2.31 & 8.66 & -17.18 & -34.88 & 26.03 & 3.28 & -11.09 \\
\hline Hungary & -25.17 & -49.11 & -54.89 & -15.24 & -53.25 & -35.11 & -61.85 & -75.63 & -20.08 & 16.59 \\
\hline Ireland & -9.91 & -41.19 & -11.78 & 0.69 & -16.20 & -16.35 & -17.67 & -12.11 & 21.33 & -1.23 \\
\hline Italy & -24.83 & 3.26 & -48.80 & -14.94 & -18.91 & -27.61 & -38.78 & 15.11 & -11.46 & -9.27 \\
\hline Luxembourg & -49.10 & -54.55 & -54.72 & -61.93 & 8.56 & 0.00 & -52.30 & 0.00 & 0.00 & -3.51 \\
\hline Netherlands & -15.06 & -8.80 & -27.41 & -14.84 & -13.46 & 2.80 & -25.71 & 0.74 & 6.67 & -1.60 \\
\hline Norway & -11.52 & -44.28 & -34.16 & -23.75 & -11.81 & 0.00 & -19.60 & 22.40 & 19.70 & 23.59 \\
\hline Poland & -8.56 & -56.83 & -40.41 & -26.96 & -0.31 & -13.92 & -63.55 & -57.96 & 24.61 & 90.27 \\
\hline Slovakia & -2.93 & 29.04 & -47.73 & -41.46 & 95.75 & 37.34 & -57.44 & 21.54 & 19.45 & -36.13 \\
\hline Slovenia & -20.12 & -73.64 & 90.47 & -65.71 & -13.90 & 15.14 & -50.71 & -27.29 & -26.86 & -11.06 \\
\hline Spain & -32.34 & 2.61 & -27.45 & -58.42 & -1.54 & -34.15 & -36.19 & 36.54 & 26.17 & -3.35 \\
\hline Sweden & -7.49 & -11.91 & -11.72 & -36.85 & 9.17 & -2.99 & -21.60 & 38.20 & 55.33 & 26.83 \\
\hline Mean & -16.70 & -12.65 & -22.20 & -28.83 & -2.24 & -7.57 & -35.65 & 3.29 & 7.07 & 4.99 \\
\hline
\end{tabular}

Table 3. Technological change.

\begin{tabular}{|c|c|c|c|c|c|c|c|c|c|c|}
\hline Country & & $\bar{A}$ & $\overline{\mathbf{M}}$ & $\begin{array}{c}\text { EGW } \\
\end{array}$ & $\mathrm{C}$ & $\mathbf{W}$ & $\mathbf{T}$ & $\mathbf{P}$ & $\mathbf{E}$ & $\mathbf{H}$ \\
\hline Austria & 43.17 & 12.27 & 66.63 & 42.94 & 27.36 & 52.92 & 24.10 & 14.61 & 2.50 & 22.17 \\
\hline Belgium & 48.15 & 16.18 & 94.53 & 42.76 & 30.05 & 75.06 & 19.67 & -8.70 & -7.93 & 21.85 \\
\hline Czech Rep. & 43.55 & 3.98 & 43.84 & 48.99 & 20.14 & 30.13 & 70.49 & 21.75 & -5.66 & 12.12 \\
\hline Denmark & 37.59 & 6.80 & 70.61 & 42.79 & 26.87 & 42.05 & 27.96 & -4.93 & 4.69 & 7.58 \\
\hline Estonia & 39.86 & 16.57 & 66.34 & 34.16 & 29.91 & 46.95 & 107.34 & 14.10 & -2.65 & 15.00 \\
\hline Finland & 42.73 & 7.06 & 78.08 & 44.53 & 23.02 & 36.09 & 97.91 & -17.37 & 9.29 & 6.60 \\
\hline France & 44.23 & 14.73 & 75.68 & 46.53 & 24.63 & 35.70 & 46.28 & 22.40 & -0.02 & 17.62 \\
\hline Germany & 37.75 & 12.42 & 65.91 & 38.17 & 19.79 & 30.19 & 53.89 & 15.76 & 5.15 & 21.89 \\
\hline Hungary & 31.19 & 27.33 & 58.20 & 70.14 & 51.73 & 17.77 & 123.79 & -26.36 & -5.11 & 5.34 \\
\hline Ireland & 34.20 & 6.04 & 62.10 & 48.95 & 21.08 & 56.28 & 14.53 & -20.82 & -4.90 & 6.72 \\
\hline Italy & 55.35 & 4.86 & 91.64 & 55.66 & 25.01 & 37.10 & 33.64 & 22.95 & -8.82 & 11.09 \\
\hline Luxembourg & 63.79 & 24.88 & 82.54 & 67.67 & 21.58 & 69.91 & 10.00 & 18.71 & 13.36 & 19.19 \\
\hline Netherlands & 55.92 & 19.37 & 73.04 & 59.42 & 24.22 & 32.18 & 33.97 & 25.13 & 6.20 & 16.97 \\
\hline Norway & 32.28 & 8.08 & 65.31 & 42.42 & 21.59 & 18.39 & 40.68 & 19.02 & 9.42 & 10.22 \\
\hline Poland & 27.67 & 28.16 & 66.18 & 66.70 & 22.72 & 25.50 & 172.53 & -26.85 & -4.96 & 4.69 \\
\hline Slovakia & 23.20 & 26.10 & 53.11 & 34.51 & 32.56 & 22.32 & 85.86 & -18.80 & -5.11 & -7.43 \\
\hline Slovenia & 64.95 & 32.28 & 445.69 & 42.85 & 27.78 & 33.65 & 121.50 & 23.18 & -4.06 & 12.99 \\
\hline Spain & 62.55 & 10.67 & 79.70 & 69.59 & 32.37 & 62.05 & 18.20 & 21.96 & 17.59 & 18.07 \\
\hline Sweden & 47.50 & 11.56 & 84.42 & 51.73 & 24.98 & 54.15 & 25.88 & 22.05 & -2.90 & 5.93 \\
\hline Mean & 43.98 & 15.23 & 90.71 & 50.03 & 26.70 & 40.97 & 59.38 & 6.20 & 0.85 & 12.03 \\
\hline
\end{tabular}

The three components of the economic growth decomposition are displayed in Tables 2-4. Efficiency change is, overall, negative for the period, while both technological change and capital accumulation are positive. When there is a technological progress, countries and sectors are farther from the production frontier; this explains the negative efficiency change found. Indeed, we see in the Tables that higher technological changes are associated with larger negative efficiency changes. Countries with the largest values for the components are Eastern and Central European countries and Luxembourg. This speaks in favour of a catching-up effect between richer and poorer countries in Europe. For the sectors, largest changes are found in the Manufacturing, Transport, and Electricity, Gas and Water sectors. That is, the most important sector in 
terms of production in Europe, and two important sectors in terms of innovation and new investments. This is also confirmed when looking at the capital accumulation per sector. All in all, the sector-based decomposition gives the option to better understand the patterns found at the country level.

Finally, the weights can be used to better understand the contribution of the sectors to the country-level indicators. For the sake of conciseness, we present in Table 5 the averages of those weights. An initial observation is that the weights are different reflecting their endogenous behaviour. Next, the weights confirm the growing importance of the Electricity, Gas and Water sector in Europe, and, to a smaller extent, the importance of the Manufacturing and Transport sectors.

Table 4. Capital accumulation.

\begin{tabular}{|c|c|c|c|c|c|c|c|c|c|c|}
\hline Country & & $\mathbf{A}$ & $\mathbf{M}$ & EGW & $\mathbf{C}$ & $\bar{W}$ & $\mathbf{T}$ & $\mathbf{P}$ & $\mathbf{E}$ & $\mathbf{H}$ \\
\hline Austria & 30.24 & 20.95 & 29.31 & 42.68 & 7.00 & 2.01 & 33.66 & -6.52 & 29.23 & 3.65 \\
\hline Belgium & 16.26 & 17.45 & 8.11 & 1.24 & 5.78 & 0.23 & 32.02 & 32.21 & 49.31 & 3.79 \\
\hline Czech Rep. & 4.00 & 8.72 & 16.13 & -4.46 & 7.56 & -8.09 & 14.06 & 2.84 & 27.93 & -14.34 \\
\hline Denmark & 36.68 & 5.10 & 44.34 & 37.96 & 0.14 & -11.41 & 26.36 & 51.02 & 46.63 & 49.79 \\
\hline Estonia & 23.71 & 27.43 & -35.87 & 162.06 & -21.99 & -33.51 & -27.61 & -9.74 & 0.17 & -14.90 \\
\hline Finland & 53.30 & 12.00 & 18.04 & 104.85 & 14.04 & 36.26 & -29.51 & 119.69 & 34.05 & 69.64 \\
\hline France & 41.29 & 11.56 & 20.74 & 88.44 & 17.27 & 5.30 & 22.89 & 12.50 & 8.97 & 2.58 \\
\hline Germany & 28.93 & 17.62 & 37.44 & 35.80 & 4.98 & 15.64 & 31.77 & 13.72 & 21.29 & 3.33 \\
\hline Hungary & -6.14 & 20.65 & 12.55 & -39.71 & -28.59 & -33.13 & -15.73 & 176.63 & -1.44 & -55.78 \\
\hline Ireland & 50.76 & 9.07 & 24.43 & 92.34 & 9.46 & 10.30 & 34.25 & 63.53 & 27.97 & 10.41 \\
\hline Italy & 19.27 & 5.60 & 7.71 & 27.59 & 1.65 & -12.37 & 9.68 & 9.64 & 34.05 & 7.36 \\
\hline Luxembourg & 17.91 & 11.54 & 2.59 & 21.39 & -7.15 & 1.98 & 26.43 & 5.41 & 17.08 & 0.48 \\
\hline Netherlands & 27.89 & 16.07 & 19.50 & 28.98 & 16.04 & 5.70 & 26.78 & 19.22 & 16.86 & 4.26 \\
\hline Norway & 60.99 & 8.42 & 47.57 & 135.52 & 44.84 & 8.65 & 26.41 & 36.77 & 36.56 & 30.11 \\
\hline Poland & 15.26 & 36.01 & 2.59 & 51.58 & -7.56 & 1.36 & 13.81 & 129.10 & -13.45 & -22.11 \\
\hline Slovakia & 49.38 & 61.22 & 58.43 & 153.55 & -21.88 & -44.25 & 39.08 & 44.93 & 51.41 & 148.85 \\
\hline Slovenia & 33.68 & 140.27 & -88.36 & 222.05 & -18.94 & -35.65 & -10.31 & -10.22 & 10.93 & -22.84 \\
\hline Spain & 9.88 & 9.55 & 0.50 & 20.11 & 3.99 & -6.03 & 12.31 & 14.99 & -27.75 & 0.26 \\
\hline Sweden & 37.03 & 17.64 & 14.40 & 53.20 & 14.99 & 12.68 & 46.35 & 15.18 & 6.24 & 42.62 \\
\hline Mean & 28.96 & 24.05 & 12.64 & 65.01 & 2.19 & -4.44 & 16.46 & 37.94 & 19.79 & 13.01 \\
\hline
\end{tabular}

Table 5. Average of the weights.

\begin{tabular}{lrrrrrrrrr}
\hline \hline Weight & A & $\mathbf{M}$ & EGW & $\mathbf{C}$ & $\mathbf{W}$ & $\mathbf{T}$ & $\mathbf{P}$ & $\mathbf{E}$ & $\mathbf{H}$ \\
\hline$\frac{y_{s}^{b}}{y^{b}}$ & 4.81 & 8.45 & 20.05 & 6.75 & 6.73 & 9.68 & 7.69 & 6.81 & 5.41 \\
$\frac{y_{s}^{b}\left(k_{s}^{b}\right)}{y^{b}\left(k^{b}\right)}$ & 6.42 & 13.11 & 33.74 & 9.47 & 8.98 & 12.30 & 10.42 & 9.93 & 7.82 \\
$\frac{y_{s}^{c}\left(k_{s}^{c}\right)}{y^{c}\left(k^{c}\right)}$ & 4.25 & 12.74 & 37.91 & 5.69 & 5.89 & 9.95 & 6.68 & 5.75 & 4.53 \\
$\frac{y_{s}^{b}\left(k_{s}^{c}\right)}{y^{b}\left(k^{c}\right)}$ & 3.39 & 6.17 & 18.85 & 4.21 & 4.06 & 5.28 & 5.57 & 5.11 & 3.77 \\
$\frac{y_{s}^{c}\left(k_{s}^{b}\right)}{y^{c}\left(k^{b}\right)}$ & 3.21 & 9.57 & 18.59 & 5.21 & 6.18 & 6.41 & 4.98 & 4.45 & 4.87 \\
\hline \hline
\end{tabular}

\section{Concluding remarks}

Studying economic growth at a disaggregated level (e.g. sectors, regions, industries) has gained popularity in the empirical macroeconomic literature. Nevertheless, it is important to know what the results at the disaggregated levels tell us about countries. This is the point of this letter that provides an intuitive and consistent aggregation scheme for several components between sectors and countries. This procedure does not require any strong assumption about the growth 
process (nonparametric spirit), and can be extended to regions or industries, and when other production factors are considered. Finally, heterogeneity between the entities is explicitly modeled.

Last, we highlight that while the disaggregated level is attractive, a major issue data availability. While it is easy to find data at national level over a rather large time period (e.g. Penn World Table), it is certainly not the case for sectors, regions, or industries. In general, only output, capital, and labor data are provided. Here then is an important shortcoming for this type of analysis. For example, for our illustration, we only observe data for a limited time period and only for European countries. Another example is Battisti, Del Gatto and Parmeter (2018) that have restricted their attention to 11 manufacturing sectors due to data availability. A last example is Walheer $(2016 a, b)$ that has used data for human capital at the country level for the sectors as a proxy variable.

\section{Acknowledgements}

We thank the Editor-In-Chief Francisco J. Delgado and the anonymous referee for their comments that have improved the paper substantially. We also thank Thibault Piron for his help.

\section{References}

Badunenko, O., and Romero-Avila, D. (2013) Financial development and the sources of growth and convergence, International Economic Review, 54(2), 629-663.

Battisti, M., Del Gatto, M., and Parmeter, C. F. (2018) Labor productivity growth: disentangling technology and capital accumulation, Journal of Economic Growth, 23, 111-143.

Charnes, A., Cooper, W. W., and Rhodes, E. (1978) Measuring the efficiency of decision making units, European Journal of Operational Research, 2, 429-444.

Daraio, C., and Simar, L. (2007) Advanced Robust and Nonparametric Methods in Efficiency Analysis: Methodology and Applications, New York, Springer.

Färe, R., and Karagiannis, G. (2017) The denominator rule for share-weighting aggregation, European Journal of Operational Research, 260, 1175-1180.

Henderson, D. J., and Russell R. R. (2005) Human capital and convergence: a productionfrontier approach, International Economic Review, 46(4), 1167-1205.

Iscan, T. B. (2015) Allocative inefficiency and sectoral allocation of labour: Evidence from U.S. agriculture, Economic Modelling, 43, 305-320.

Kumar, S., and Russell, R. (2002) Technological change, technological catch-up, and capital deepening: relative contributions to growth and convergence, American Economic Review, 92(3), 527-548.

Magalhaes, M., and Afonso. O. (2017) A multi-sector growth model with technology diffusion and networks, Research Policy, 46, 1340-1359.

Solow, R. M. (1956) A Contribution to the Theory of Economic Growth, Quarterly Journal of Economics, 70(1), 65-94.

Walheer, B. (2016a) A multi-sector nonparametric production-frontier analysis of the economic growth and the convergence of the European countries, Pacific Economic Review, 21(4), 498-524.

Walheer, B. (2016b) Growth and Convergence of the OECD countries: A Multi- Sector Production-Frontier Approach, European Journal of Operational Research, 252(2), 665675.

Walheer, B. (2018a) Aggregation of metafrontier technology gap ratios: the case of European sectors in 1995-2015, European Journal of Operational Research, 269, 1013-1026. 
Walheer, B. (2018b) How foreign investments contribute to economic growth of industrial parks in China: a production-frontier decomposition approach, Applied Economics Letters, 26(4), 281-285.

Walheer, B. (2018c) Labour productivity growth and energy in Europe: a production-frontier approach, Energy, 152, 129-143

Walheer, B. (2019) Scale, congestion, and technical efficiency of European countries: a sectorbased nonparametric approach, Empirical Economics, 56, 2025-2078.

Zeira J., and Zoabi, H. (2015) Economic growth and sector dynamics, European Economic Review, 79, 1-15.

Zelenyuk, V. (2016) Aggregation of scale efficiency, European Journal of Operational Research, 240, 269-277. 